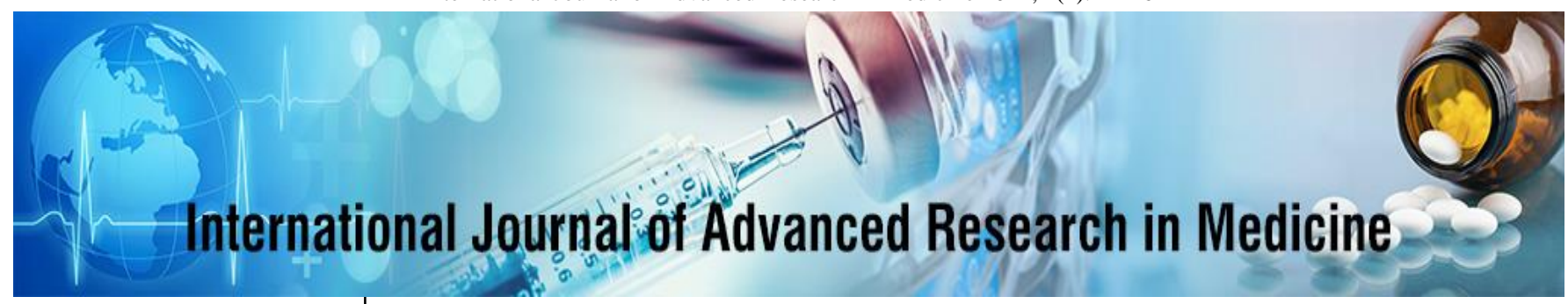

E-ISSN: 2706-9575

P-ISSN: 2706-9567

IJARM 2022; 4(1): 44-46

Received: 25-11-2021

Accepted: 27-12-2021

\section{Jayant Kumar}

MD Pathology, NSCB Zonal Hospital, Mandi Himachal

Pradesh, India

\section{Vikas Thakur}

MD Community Medicine,

NSCB Zonal Hospital, Mandi

Himachal Pradesh, India
Corresponding Author: Jayant Kumar MD Pathology, NSCB Zonal Hospital, Mandi Himachal Pradesh, India

\section{Prevalence of microcytic hypochromic anaemia among teenagers}

\author{
Jayant Kumar and Vikas Thakur
}

DOI: https://doi.org/10.22271/27069567.2022.v4.i1a.321

\begin{abstract}
Background: Anaemia is the most common nutritional disorder worldwide. According to WHO adolescent age group is defined as life span between 10-19 years. Hence; the present study was conducted for assessing the prevalence of microcytic hypochromic anaemia among teenagers.

Materials \& Methods: A total of 100 teenagers within the age arrange of 12 to 18 years were enrolled. The following data were collected: age, gender, and the results of a CBC and $\mathrm{Hb}$ electrophoresis. Samples obtained by venipuncture were collected and processed. Peripheral blood film examination was also done. Microcytic hypochromic examination was done. All the results were record and analysed by SPSS software.

Results: Microcytic hypochromic anaemia was found to be present in 15 percent of the patients. Out of 15 patients with presence of Microcytic hypochromic anaemia, 33.33 percent of the patients were males while the remaining were females.

Conclusion: Anaemia is a public health problem among school adolescents in the area. School-based intervention among school adolescents based on identified determinant factors will be very important for the prevention and control of anemia among the group.
\end{abstract}

Keywords: anaemia, microcytic, hypochromic

\section{Introduction}

Anaemia is the most common nutritional disorder worldwide. According to WHO adolescent age group is defined as life span between 10-19 years. In India the prevalence of anaemia among adolescent girls were $56 \%$ and these amounts to an average 64 million girls at any point in time. The major risk factors identified from the above studies were socio-economic status, blood loss during menstruation, nutritional status, hand hygiene and worm infestation [1- 3]. Nutritional needs of girls during adolescent period are generally ignored leading to stunting and poor health. One of the major consequences of the physiological changes and the nutritional neglect which happens during this period is anaemia. In a tropical country like India helminthic infestation is very common which can lead to chronic blood loss which in turn results in anaemia. Early diagnosis and, more importantly, identifying the etiology of anemia are fundamental not only for adequate treatment but also to design public policies aimed at the promotion and protection of health ${ }^{[4-6]}$. Hence; the present study was conducted for assessing the prevalence of microcytic hypochromic anaemia among teenagers.

\section{Materials \& Methods}

The present study was conducted for assessing the prevalence of microcytic hypochromic anaemia among teenagers. A total of 100 teenagers within the age arrange of 12 to 18 years were enrolled. The following data were collected: age, gender, and the results of a CBC and $\mathrm{Hb}$ electrophoresis. Samples obtained by venipuncture were collected and processed. Peripheral blood film examination was also done. Microcytic hypochromic examination was done. All the results were record and analysed by SPSS software.

\section{Results}

A total of 100 teenagers were analysed. Microcytic hypochromic anaemia was found to be present in 15 percent of the patients. Out of 15 patients with presence of Microcytic hypochromic anaemia, 33.33 percent of the patients were males while the remaining were females. 
Table 1: Prevalence of microcytic hypochromic anaemia

\begin{tabular}{|c|c|c|}
\hline Microcytic hypochromic anaemia & Number & Percentage \\
\hline Present & 15 & 15 \\
\hline Absent & 85 & 85 \\
\hline Total & 100 & 100 \\
\hline
\end{tabular}

Table 2: Gender-Wise Distribution of patients with microcytic hypochromic anaemia

\begin{tabular}{|c|c|c|}
\hline Gender & Number & Percentage \\
\hline Males & 5 & 33.33 \\
\hline Females & 10 & 66.67 \\
\hline Total & 15 & 100 \\
\hline
\end{tabular}

\section{Discussion}

Anaemia during childhood is one of the biggest public health problems worldwide. Insufficient or abnormal production of hemoglobin, loss of iron and excessive destruction of red blood cells are the most common causes of anaemia. Among the reasons of anaemia, iron deficiency accounts for $50 \%$ of anaemia cases in developing countries. Affected individuals present a wide range of clinical problems, including delayed neuropsychomotor progression, impaired cellular immunity and reduction of intellectual capacity. ${ }^{8-10}$ Microcytic, hypochromic anemia, as the name suggests, is the type of anemia in which the circulating RBCs are smaller than the usual size of RBCs (microcytic) and have decreased red color (hypochromic). The most common cause of this type of anemia is decreased iron reserves of the body which may be due to multiple reasons. This may be due to decreased iron in the diet, poor absorption of iron from the gut, acute and chronic blood loss, increased demand for iron in certain situations like pregnancy or recovering from major trauma or surger. ${ }^{10-} 12$ Hence; the present study was conducted for assessing the prevalence of microcytic hypochromic anaemia among teenagers.

A total of 100 teenagers were analysed. Microcytic hypochromic anaemia was found to be present in 15 percent of the patients. Kyaw Htet $\mathrm{M}$ et al A cross-sectional survey was conducted on 1269 subjects to obtain complete blood count, anthropometry and socioeconomic characteristics were obtained by questionnaire. Using red cell indices, we applied Bessman's, and Green and King's index classification to differentiate the types of anaemia. Electrophoresis was also done on a subsample $(n=228)$. Stunting was $21.2 \%$ and wasting was $10.7 \%$ respectively. Prevalence of anaemia was $59.1 \%$ and was mainly microcytic. Green and King's index showed $35.8 \%$ were iron deficient. Electrophoresis revealed 36 cases of $\mathrm{Hb} \mathrm{E}$ haemoglobinopathy in the subsample. Anaemia is still a major nutrition problem in Myanmar. The reasons for this high prevalence should be explored and properly addressed [12].

Out of 15 patients with presence of Microcytic hypochromic anaemia, 33.33 percent of the patients were males while the remaining were females. Siva PM et al estimated prevalence of anaemia and its associated factors among adolescent girls of central Kerala, India. A cross-sectional study was conducted among 257 adolescent girls. Blood samples were analysed using an auto-analyser and stool examination for ova or cyst was done under microscopy. Diagnosis of anaemia was established when haemoglobin was less than $12 \mathrm{gm} / \mathrm{dl}$. The prevalence of anaemia was $21 \%$. Risk factors associated with anaemia in the univariate analysis were presence of ova or cyst in stool $(\mathrm{p}=0.003, \mathrm{OR}=2.94)$ and number of pads per day during menstruation $(\mathrm{p}=0.004)$. Protective factors were hand washing after toileting ( $\mathrm{p}=$ $0.021, \mathrm{OR}=0.311)$, hand washing before food intake $(\mathrm{p}=$ $0.026, \mathrm{OR}=0.5)$, foot wear usage $(\mathrm{p}=0.022, \mathrm{OR}=0.25)$ and jaggery consumption (0.042). The factors which were significant in logistic regression were worm infestation, number of pads per day, washing hands before food intake and foot wear usage. Worm infestation and number of pads per day during menstruation were found to be risk factors for anaemia ${ }^{[13]}$.

\section{Conclusion}

Anaemia is a public health problem among school adolescents in the area. School-based intervention among school adolescents based on identified determinant factors will be very important for the prevention and control of anemia among the group.

\section{References}

1. Gebreweld A, Bekele D, Tsegaye A. Hematological profile of pregnant women at St. Paul's Hospital Millennium Medical College, Addis Ababa, Ethiopia. BMC Hematol. 2018;18:15.

2. Needs T, Gonzalez-Mosquera LF, Lynch DT. StatPearls [Internet]. StatPearls Publishing; Treasure Island (FL): Jul 18, 2021. Beta Thalassemia.

3. Farashi S, Harteveld CL. Molecular basis of $\alpha$ thalassemia. Blood Cells Mol Dis. 2018 May;70:43-53.

4. Bairwa M, Rajput M, Sachdeva S. Modified kuppuswamy's socioeconomic scale: Social researcher should include updated income criteria, 2012. Indian J Community Med Off Publ Indian Assoc Prev Soc Med. 2013;38(3):185-86.

5. WHO | BMI-for-age (5-19 years) [Internet]. WHO. [cited 2016 Jun 10]. Available from: http://www.who.int/growthref/who2007_bmi_for_age/e $\mathrm{n} /$

6. Guidelines for Control of Iron Deficiency Anaemia [Internet]. 1-38 p. Available from: http://www.unicef.org/india/10._National_Iron_Plus_In itiative_Guidelines_for_Control_of_IDA.pdf.

7. Benoist B de, McLean E, Egll I, Cogswell M, others. Worldwide prevalence of anaemia 1993-2005: WHO global database on anaemia. [Internet]. World Health Organization; 2008 [cited 2014 Sep 21]. Available from:

http://www.cabdirect.org/abstracts/20093013528.html.

8. Verma M, Chhatwal J, Kaur G. Prevalence of anemia among urban school children of Punjab. Indian Pediatr. 1. 998;35(12):1181-86.

9. Nead KG, Halterman JS, Kaczorowski JM, Auinger P, Weitzman M. Overweight children and adolescents: A risk group for iron deficiency. Pediatrics. 2004;114(1):104-08.

10. Kaur S, Deshmukh PR, Garg BS, et al. Epidemiological correlates of nutritional anemia in adolescent girls of rural Wardha. Indian J Community Med. 2006;31(4):255-58.

11. Warner MJ, Kamran MT. StatPearls [Internet]. StatPearls Publishing; Treasure Island (FL): Aug 11, 2021. Iron Deficiency Anemia.

12. Kyaw Htet M, Dillon D, Akib A, Utomo B, Fahmida U. Microcytic anaemia predominates in adolescent school 
girls in the delta region of Myanmar. Asia Pac J Clin Nutr. 2012;21(3):411-5.

13. Siva PM et al. Prevalence of Anaemia and Its Associated Risk Factors Among Adolescent Girls of Central Kerala. J Clin Diagn Res. 2016 Nov;10(11):LC19-LC23. 